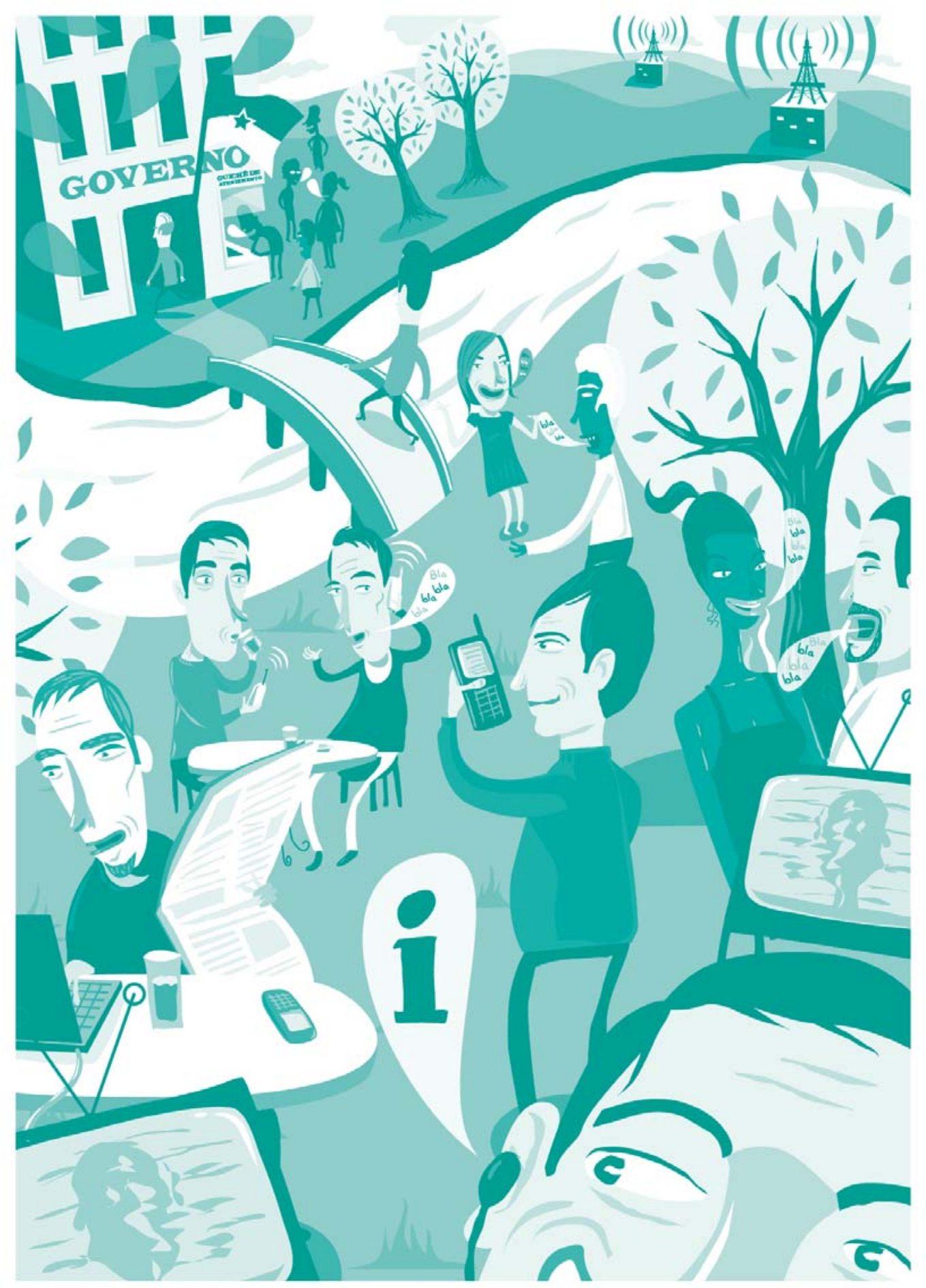




\section{Jornalismo Público: por uma nova relação com os públicos}

Paulo Celestino da Costa, filho

- Especialista em Gestão Estratégica de Comunicação Organizacional e Relações Públicas (Gestcorp) pela Escola de Comunicações e Artes da Universidade de São Paulo (ECA-USP)

- Bacharel em Jornalismo pela Universidade Federal do Rio Grande do Norte (UFRN)

- Editor-executivo da Organicom

- paulocostafilho@uol.com.br

-paulocostafilho@yahoo.com.br 


\section{Resumo}

O Jornalismo Público (JP), surgido no início dos anos 1990, representa um movimento de questionamento dos principais valores conceituais do jornalismo informativo. Seu principal objetivo é promover uma nova atitude de ligação para com os públicos. Mais do que uma estratégia para restabelecer a confiança e credibilidade dos meios com seus usuários, o JP entende a mídia como peça-chave na constituição do novo espaço público característico da pós-modernidade.

PALAVRAS-CHAVE: JORNALISMO PÚBLICO • JORNALISMO CIDADÃO - ESPAÇO PÚBLICO • CIDADANIA E MÍDIA • JORNALISMO E POLÍTICA • TV CULTURA

\section{Abstract}

Public Journalism (PJ) emerged in the beginning of the 90's, when the main conceptual values of the informative journalism were discussed. The main aim of PJ is to improve a new way of connection between journalism and the public. More than a strategy to make a reliable media, PJ understands the media like a key instrument to constitute a new post-modern public sphere.

KEYWORDS: PUBLIC JOURNALISM - CIVIC JOURNALISM - PUBLIC SPHERE - CITIZENSHIP AND MEDIA - JOURNALISM AND POLITICS - TV CULTURA

\section{Resumen}

El Periodismo Público (PP), surgido al inicio de los años 1990, representa un movimiento de cuestionamiento de los principales valores conceptuales del periodismo informativo. Su principal objetivo es promover una nueva actitud de conexión con los públicos. Más que una estrategia para restablecer la confianza y credibilidad de los medios con sus usuarios, el PP entiende a los medios como pieza clave en la constitución del nuevo espacio público característico de la post-modernidad.

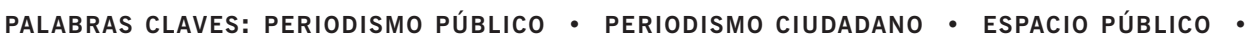
CIUDADANÍA Y MEDIOS • PERIODISMO Y POLÍTICA • TV CULTURA 
"Onde estão os sujeitos falantes do povo?

O que eles sofrem, fazem e dizem?"

Manuel Carlos Chaparro

$\mathrm{N}$ o início dos anos 1990, surgiu nos Estados Unidos um polêmico movimento dentro da imprensa. Jornalistas, professores e, principalmente, alguns meios resolveram encampar projetos que não só questionavam e reviam muitos dos conceitos fundamentais do jornalismo, como também, a partir das reflexões, propunham uma nova atitude de relacionamento para com os usuários.

O tradicional jornalismo, puramente informativo, passou a ser contestado. O pressuposto era de que os públicos se tornaram apáticos às suas formas, posturas e procedimentos. A informação, em seu invólucro jornalístico representado pela notícia, embora fosse abundante, não estava sendo suficiente para mudar a situação apresentada nestas notícias.

Conceitos como a objetividade e o afastamento do jornalismo do fato relatado, embora sejam elementos que outrora deram dignidade e legitimidade à imprensa como empresa, agora eram colocados na vitrine. Ao mesmo tempo, havia sinais de que o jornalismo vinha sendo influenciado por diversas mudanças de ordem econômica, política e social, modificando sobremaneira o fazer jornalístico.

O Jornalismo Público, ou cívico, como também é conhecido, parece ter sido uma reação a todos estes fenômenos, além de levar em consideração fatos concretos e tangíveis como tiragem e audiência e, ainda mais, credibilidade. Na busca de fundamentálo e torná-lo uma prática real, professores, editores e jornalistas saíram a campo, abriram mão da postura-padrão, associaram-se a instituições e se lançaram em um novo relacionamento com o público. Como em toda reforma, eles e suas teorias não passaram incólumes.

Os jornalistas públicos partem da premissa de que é necessário reanimar o debate público, pois a informação por si só não é suficiente. É necessário interpelar o cidadão para que ele participe. Deste modo, propõe-se uma nova dinâmica da vida em sociedade, tendo a imprensa um fundamental papel não só como mediadora, mas como espaço de mediação. De simples observadores isentos, os jornalistas passam a ser atores. Portanto, diz respeito direto às relações entre política e jornalismo.

Um dos papéis do Jornalismo Público seria construir a cidadania. Mas se alega que o Jornalismo é, na essência, um instrumento público, cívico, cidadão. O trabalho de um jornalista é, antes de tudo, para a sociedade. Mas será que os meios e os jornalistas conseguem manter este compromisso, manter sua autonomia quando se dão conta 
que a imprensa hoje se constitui como empresa ou está ligada a grandes grupos econômicos, com todas as suas vontades e interesses?

Algumas organizações brasileiras começam a aderir e utilizar os conceitos teóricos do Jornalismo Público americano. Há até a suspeita de que elas estão "abrasileirando" os conceitos. E isto não fica apenas restrito a pequenos jornais ou instituições. A TV Cultura, uma das mais importantes TVs públicas do País, já estampa seu telejornalismo com o slogan do Jornalismo Público.

Portanto, a proposta desse artigo, derivado do trabalho de conclusão do curso de Gestão Estratégica em Comunicação Organizacional e Relações Públicas (Gestcorp), orientado pela Profa. Heloiza Matos, foi tentar identificar - por meio de uma revisão conceitual e da leitura crítica de obras recentes no campo da Comunicação - quais são as principais características e questionamentos deste "novo jornalismo", tanto nos Estados Unidos como na América Latina. Deste modo, também vamos em busca de algumas indicações de quais são as possibilidades de alterações no relacionamento do jornalismo com o seu público, bem como de identificar as linhas político-filosóficas que podem legitimar este novo relacionamento.

\section{Conceituação}

Os últimos anos da década de 1980 trouxeram à cena, nos Estados Unidos, uma nova proposta para o jornalismo. Em um tom quase revolucionário, muitos dos novos procedimentos eram muito diferentes da tradicional prática. Esse "novo jornalismo" se baseava na reavaliação dos valores essenciais do jornalismo, contestando o status quo dos produtores de notícias. Para o professor Nelson Traquina, de Portugal, esse é um dos mais importantes movimentos do jornalismo nos últimos 30 anos.

Essa nova proposta é conhecida por diferentes nomes: "jornalismo comunitário" (CRAIG, 1995), "jornalismo de serviço público" (SHEPARD, 1994); "jornalismo cívico” (LAMBETH e CRAIG, 1995). Mas, para Traquina, a centralidade do termo "cidadão” em sua proposta o leva a preferir a designação “jornalismo cívico” (TRAQUINA,

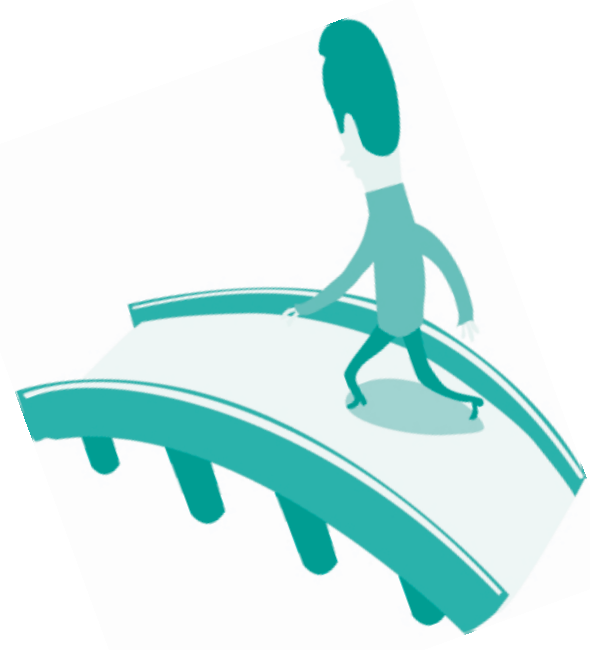


JORNALISMO PÚBLICO: POR UMA NOVA RELAÇÃO COM OS PÚBLICOS • PAULO CELESTINO DA COSTA, FILHO

2001, p. 171). Porém, seus principais teóricos nos Estados Unidos utilizam Jornalismo Público (ROSEN, 1994; MERRITT, 1995), termo ao qual vamos nos ater daqui por diante.

O movimento surge entre editores e professores como uma reação à perda de credibilidade dos media, às baixas tiragens dos jornais e, principalmente, em contraponto às eleições americanas de 1988, nas quais os jornalistas se mostraram incapazes de perceber e reagir às operações políticas, além da baixa participação política dos cidadãos nos EUA.

Para Traquina, crítica acumulada em mais de cem anos dos media, reforçada nos últimos 25 anos pelos estudos realizados na academia, gerou uma quantidade significativa de munições para desafiar o status quo (TRAQUINA, 2001, p. 171). Isso gerou um arcabouço teórico para a sustentação do movimento.

\section{Um jornalismo corretamente ligado}

Uma das principais bandeiras do Jornalismo Público é uma atitude diferente no relacionamento com o público. No caso americano, novas formas de atuação foram testadas para se captar, processar e publicar as informações.

Com o apoio financeiro de instituições, mais de duzentos projetos de Jornalismo Público procuraram renovar o jornalismo norte americano e contribuir para dinamizar a participação dos cidadãos na vida pública. Utilizando diversas técnicas de auscultação do público, as empresas ouviram os cidadãos para identificar sua agenda. Em alguns casos, tornam-se parceiros ativos na procura de soluções para os problemas da comunidade (TRAQUINA, 2001, p. 176).

Uma das principais preocupações dos jornalistas públicos é a retomada da conexão com o público, tratada no livro Getting The Connections Right, uma das publicações do professor Jay Rosen sobre o assunto. Ele traz para o centro das discussões um dos valores do jornalismo: o afastamento (detachment).

Para Rosen, um dos principais efeitos do afastamento é fazer com que os jornalistas não tenham alternativa a não ser esquecer suas identidades como cidadãos, levandoos a extremos pontos de isolamento. Ele ainda aponta que, para manter as separações certas, os jornalistas até mesmo "esquecem" que votam.

O que Rosen define como conexões são todas as relações entre notícias e opiniões, fatos e valores, entre o produto editorial e a atividade como negócio, a imprensa e o sistema político, a crise ocupacional e a crise espiritual e, particularmente, a conexão primordial entre o jornalismo e o público. 
Ele considera que a idéia de se desenvolver as conexões certas é difícil, pois realmente a separação permanece como algo criticamente importante no jornalismo. Ele não deixa de considerar que há diferença entre fazer jornalismo e fazer política, entre observação e ação. Dentro disto, há na objetividade um valor que deve ser mantido. Mas o que ele critica é uma certa "esterilidade" nos relacionamentos, principalmente para com o público.

Rosen então busca definir esta nova prática. "Se o jornalismo tradicional se preocupa em se manter propriamente afastado, o Jornalismo Público se preocupa em se tornar propriamente ligado".

E esta ligação passa por uma nova postura cívica do jornalista, com um novo papel no qual uma de suas principais missões é ressuscitar a vida pública por meio do reforço da cidadania e da melhoria do debate público. O jornalista passa a ser um ator social atuando com os outros. Rosen advoga que o jornalismo precisa ser mais "público", isto é, "tentar encontrar maneiras de interessar um maior número de cidadãos na vida pública enquanto tornamos a vida pública mais interessante, encorajar o discurso sério a tornar-se 'mais público' enquanto tornamos o discurso público mais sério” (ROSEN, 1991, p. 269, apud TRAQUINA, p. 180).

O Jornalismo Público é, assim, para Rosen, a disponibilidade para "quebrar com velhas rotinas, um desejo de estar ligado de novo com os cidadãos e as suas preocupações, uma ênfase na discussão séria como atividade principal na política democrática, e um foco nos cidadãos como atores do drama político em vez de espectadores" (1994, p. 376, apud TRAQUINA, 2001, p. 180).

Carlos Manoel Chaparro (2001), da Universidade de São Paulo, também chama a atenção para uma dimensão perdida do jornalismo, a do próprio público. "Apesar de quase não entrar nos agendamentos jornalísticos, o povo produz acontecimentos e, com eles, conflitos, cultura - fatos, falas, artes e saberes que precisam ser captados, compreendidos, narrados". Para o professor, perguntas como "onde estão os sujeitos falantes do povo? O que eles sofrem, fazem e dizem?” agora são raras nas redações. Portanto, "em vez de repudiar as fontes, importa aumentar-lhes o elenco, a diversidade, a capacidade de produzir e colocar nos circuitos sociais os discursos por meio dos quais lutam e interferem no presente".

Para Heloiza Matos, uma das maiores estudiosas da comunicação pública e política além das relações entre imprensa e opinião pública no Brasil, não é mais possível pensar no jornalismo como uma profissão unificada. Na atual explosão da informação, a função do jornalismo se desloca da mera disseminação de mensagens para a oferta de orientação, e a ênfase da notícia, do conteúdo para o contexto.

“...o ambiente fragmentado da midia, o advento dos novos formatos da mídia basea- 
dos na multimídia e na interatividade, não permitem essa classificação unitária. Podemos observar hoje a existência de um jornalismo de orientação (com análise, background, crítica) e de um jornalismo instrumental, que visa oferecer informações especializadas para públicos interessados". (MATOS, 2004)

Ela detecta ainda uma tendência de quebra do jornalismo da era da mass media, "guiado, controlado pelo debate público, mas que pode se incumbir da fundação de definir e dirigir a agenda pública". "O 'Jornalismo' - se ainda existe como tal - está ficando dividido. De um lado a necessidade de information brokers e, de outro, de diretores e condutores do debate público".

Outro defensor de uma nova postura de relacionamento é o jornalista americano Davis Merritt, que, além de teorizar sobre o Jornalismo Público, como editor aplicou suas idéias no The Wichita Eagle. Para Traquina (2001), o que Merritt e Rosen compartilham é a "mesma visão de democracia participativa, defendendo um papel mais ativo do jornalismo na construção de um espaço público mais vibrante e na resolução dos problemas da comunidade".

Merritt vê como essencial e simbiótica a relação entre democracia e jornalismo. Segundo ele, o jornalismo tem ignorado as suas obrigações para com uma vida pública efetiva e que esta falência tem sido um contribuinte para o atual "mal-estar" da vida pública. Para o editor, o jornalismo pode, e deve, ser uma "força fundamental" na "revitalização da vida pública". Mas ele defende que é necessário haver uma mudança fundamental na profissão para conseguir esse objetivo (TRAQUINA, 2001. p. 177). Para Merritt:

"Numa sociedade de individuos dispersos e abarrotados com informação descontextualizada, uma vida pública efectiva precisa ter uma informação relevante que é partilhada por todos, e um lugar para discutir as suas implicações. Somente jornalistas livres e independentes podem-mas habitualmente não conseguem-providenciar estas coisas. Do mesmo modo, a vida pública efetiva requer a atenção e o envolvimento de cidadãos conscienciosos, que eles só podem providenciar. Por outro lado, se as pessoas não estão interessadas na vida pública, elas não têm qualquer necessidade dos jornalistas nem do jornalismo". (MERRITT, 1995, p. XI, apud TRAQUINA, 2001, p. 177)

Assim como Rosen, Merritt propõe uma redefinição do jornalismo. "Tem de ser fundamental a adoção de um papel para além das notícias” (MERRITT, apud TRAQUINA, p. 177). Merritt apresenta o conceito de objetividade como um dos principais alvos a abater, apontando-o como responsável para a valorização do afastamento. Para ele, o valor do equilíbrio tem conduzido os jornalistas a enquadramentos que apresentam as questões de forma viciada, privilegiando os lados extremos (MERRITT, apud TRAQUINA, 2001, p. 178). 
Traquina observa que, "assim, para o jornalismo cívico, torna-se um imperativo que o jornalismo encoraje o envolvimento do cidadão na vida pública, desenvolvendo nos jornalistas uma nova perspectiva - a perspectiva do "participante justo" (fair-minded participants) - com a utilização de um novo conjunto de instrumentos de trabalho".

Traquina (2001, p. 179) faz então uma síntese das proposições de Merritt:

“...escreve que, historicamente, o papel de cão de guarda tem servido bem ao jornalismo e à democracia (1995, p. 21); defende que o objetivo tradicional do jornalismo-dar as notícias ('telling the news') - não deve ser abandonado (1995, p. 114); alerta que a adoção da perspectiva do 'participante justo' no lugar do 'observador desprendido', que Merritt associa ao conceito de objetividade, não implica um envolvimento direto nos acontecimentos públicos".

Assim como Rosen, o objetivo do jornalismo cívico, na opinião de Merritt, é tornarse "ligado corretamente". Porém, Traquina levanta um questionamento pertinente: "Mas o que é corretamente? Quando é que o 'participante’ torna-se ativista?”.

Segundo Traquina, estas dúvidas provocam as principais reservas em relação ao Jornalismo Público e certamente a maior controvérsia em relação a este movimento.

\section{Uma nova demanda político-filosófica}

Um dos trabalhos importantes na continuidade do pensamento do Jornalismo Público é encontrado na América do Sul. A professora Ana Maria Miralles Castellanos, da Universidade Pontifícia Bolivariana, tem avançado principalmente no que diz respeito a uma proposta política para o Jornalismo Público ${ }^{1}$. Neste caminho, a pesquisadora apresenta alguns caminhos que buscam estruturar as bases deste novo relacionamento e dirimir as principais críticas feitas ao Jornalismo Público.

A ligação com o público é uma das principais pedras no caminho do Jornalismo Público. Para Castellanos, isso não pode ser feito sem que a discussão passe pela construção do cidadão, baseada sempre na busca pela deliberação dos assuntos públicos na esfera pública. Sua defesa é de que o público deve ser construído, tendo como valor principal a cidadania (grifo nosso).

Uma das proposições de Castellanos é a da distinção entre dois conceitos, o do jornalismo puramente informativo e o do interesse público informativo. Segundo ela, se a

1 CAStellanos, Ana Maria Miralles. La construcción de lo público desde el periodismo cívico. Disponível em: <http://www.eca.usp.br/alaic/Congreso1999/2gt/Ana\%20Maria\%20Miralles.doc>. Acesso em: 05 jul. 2006. Tradução nossa. 


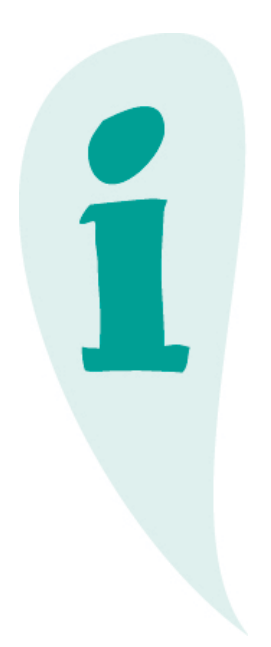

filosofia criada pelo jornalismo informativo não levou em consideração a idéia de interesse público informativo - embora o utilize como slogan - é porque ainda não havia subsídios para tal. Isto estaria sendo criado, hoje, pelas recentes discussões relativas à esfera pública e à participação do público nas deliberações, refletidas nos esforços de Dewey, Habermas, Arendt e Rorty.

Sua argumentação é de que a imprensa e sua cultura profissional jornalística não foram bem sucedidas em tentar criar uma esfera autônoma da esfera política, mesmo que em nome desta distinção tenha sido desenvolvida essa cultura e mesmo que ela tenha desempenhado um importante papel na época de ruptura com o poder absolutista.

Porém, se a imprensa hoje conta com os ideais de liberdade de opinião e de empresa, ainda falta o compromisso social por parte dessa mesma imprensa, algo que nem a formulação do direito à informação contribuiu para criar. Ainda para reforçar, "tampouco hoje se pode admitir que a profissionalização dos fazeres informativos exime o jornalismo de responder por um modelo de vida em sociedade, qualquer que seja este".

Essa crítica resvala então, assim como em outros autores anteriormente colocados, em um dos principais conceitos do jornalismo, a objetividade, além do próprio modo de produção das notícias. Para a autora, as fontes de informações relacionadas com os poderes públicos e econômicos têm lugar privilegiado, sobrando ao cidadão comum aparecer somente como vítima.

Para Castellanos, um dos problemas do jornalismo informativo é que ele "pressupõe a existência de uma esfera pública funcionando, na qual os assuntos comuns são continuamente reconhecidos e discutidos". Deste modo, "se pensa que é suficiente somente apresentar notícias, acrescentar alguns testemunhos, publicar editoriais e realizar algumas entrevistas com funcionários".

Com essa idéia de a informação precisar de algo além dela mesma, Castellanos corrobora idéias de Christopher Lasch, que defende que a informação não é suficiente para a sustentação da democracia, sendo necessário gerar o debate público para incrementá-la e desenvolvê-la. 
Portanto, para a autora, o que está em jogo no Jornalismo Público é o projeto político que o sustenta. O Jornalismo Público partiria então da premissa de que não é suficiente a boa informação para reanimar o debate público: é necessário interpelar o cidadão para que ele participe, propondo-se uma nova dinâmica da vida em sociedade. "Neste caso, se reconhecem funções explícitas em torno de um modelo de democracia que se aproxima mais da participação cidadã que o inconfesso sistema liberal, o qual se pretendia neutro".

E deste ponto a autora vai buscar em Rosen o seguinte questionamento: "como construtores da esfera pública, podem os jornalistas continuar operando sem uma filosofia pública?” (ROSEN, apud CASTELLANOS, 1999). Tomando como base essas idéias, chega-se à conclusão de que não é em vão que a maioria dos projetos de Jornalismo Público nos Estados Unidos é de caráter eleitoral e pretende envolver o cidadão em um debate público sobre os temas da cidade, e não sobre o que os condutores de campanha querem que os cidadãos pensem em termos de rentabilidade eleitoral.

Para a autora, na suposição de representarem os interesses de seus leitores, os meios estariam promovendo uma verdadeira inversão ao selecionar os temas não do ponto de vista das preocupações cidadãs, mas somente sob o ângulo dos experts, além da outra agenda dominante, a dos políticos. "Isto tem produzido indiferença, distanciamento, cinismo e a 'consciência' de que os cidadãos não podem fazer nada”.

Assim, deve o Jornalismo Público chegar apenas à promoção da deliberação ou deve animar os seus públicos à ação, marcada pelo paradigma da democracia participativa? Para Castellanos, a resposta para esta pergunta leva a definir o modelo de democracia que dá suporte ao Jornalismo Público. Para a professora, o mais próximo da filosofia política à idéia de Jornalismo Público é a construção da democracia deliberativa. Ela cita Habermas, que define o conceito:

"A noção de uma democracia deliberativa está enraizada no ideal intuitivo de uma associação democrática na qual a justificação dos limites e condições dessa associação procedem mediante a argumentação e o pensamento público entre os cidadãos iguais". (HABERMAS, apud CASTELLANOS, 1999)

Ainda recorrendo aos debates de filosofia política, Anthony Giddens prefere a expressão "democracias dialogantes". Para Castellanos, esta posição é mais próxima do Jornalismo Público porque, segundo Giddens, na democracia dialogante não está implícito o próprio ato da fala.

"Pelo contrário, o potencial da democracia dialogante está na difusão da capacidade social de reflexão, como requisito das atividades cotidianas e a persistência de formas mais amplas de organização coletiva". (GIDDENS, apud CASTELLANOS, 1999) 
Portanto, a capacidade comunicativa do Jornalismo Público tem um caráter muito mais aberto e menos rígido que o da comunidade deliberativa de Habermas.

Para Castellanos, parece não haver mais dúvidas de que a tarefa principal do Jornalismo Público é a construção da cidadania. E que o seu compromisso maior é com a deliberação pública. Ainda segundo a autora, o ativismo do jornalista público consiste em promover o diálogo público com estratégias diferentes de informação. Se ele leva os cidadãos à ação, é um resultado importante. Assim, Castellanos sintetiza os conceitos do Jornalismo Público:

"Os propósitos do jornalismo cívico giram em torno da idéia de reconectar os cidadãos à vida pública, potencializar a capacidade de deliberação da cidadania, oferecer informação com vistas à participação, apoiar os processos cidadãos com uma boa cobertura e, especialmente, um adequado seguimento, dar elementos para a criação de capital social, ao tempo que põe os meios em qualidade de atores e promotores do diálogo social. Tudo isto sem favorecer uma solução ou interesse particular. De forma particular, distingue entre audiências e públicos, entre leitores e cidadãos".

Castellanos cita como uma das formas de Jornalismo Público a participação cidadã na construção da agenda informativa dos meios. Essa agenda trata de estabelecer antecipadamente os temas de interesse público com as próprias pessoas, por meio das pesquisas ou da configuração dos painéis de cidadãos. Eles estabelecem as prioridades informativas e enfoques para os trabalhos jornalísticos junto com editores e jornalistas. Além disso, uma das preocupações é introduzir o ponto de vista do cidadão nestas histórias.

A autora conclui que o Jornalismo Público, ao se inscrever diretamente na esfera da ação cívica mediante a deliberação, é um modelo de jornalismo que se vai construindo em uma prática que retroalimenta o conceito. E o sucesso da implantação de seu projeto vai depender do arranjamento adequado das premissas filosóficas do Jornalismo Público e de sua leitura a partir de metodologias apropriadas para interpretá-las.

\section{O Jornalismo Público no Brasil}

Os projetos de jornalismo que podem se encaixar nos moldes do chamado Jornalismo Público ainda são poucos no Brasil. Em um projeto de pesquisa, o professor Luiz Martins da Silva ${ }^{2}$, da Universidade de Brasília (UnB), vem tentando conceituar Jornalismo Público a partir da experiência brasileira. Ele considera que o Jornalismo Público ainda não encontrou no Brasil nem uma tradução definitiva nem uma compreensão do que representa como função, área de cobertura e campo profissional.

2 SILVA, Luiz Martins. Jornalismo Público: o social como valor-notícia. Texto apresentado no GT de Políticas e Estratégias de Comunicação da Compós, 2002. 
Para Silva (2002), a imprensa brasileira não estaria simplesmente copiando conceitos ou fazendo uma adaptação de um paradigma pronto. Dessa forma, pode-se dizer que, no Brasil, o Jornalismo Público emerge com características próprias.

Silva ressalta certas confusões que podem ocorrer em decorrência da própria comutação que se faz, no Brasil, em torno do setor público, em geral associado com as esferas estatal e governamental. Na opinião de Silva, seria uma imprecisão imaginar que Jornalismo Público seria aquele praticado desde as redações a serviço dos governos Federal e Estadual ou por emissoras estatais.

Portanto, no Brasil, não houve uma adesão estrita ao gênero, mas também não houve rejeição. No seu entender, houve um outro tipo de fenômeno representado no enorme interesse para com os projetos de impacto social e para com organizações e pessoas que dedicam a vida a grandes causas ou campanhas.

Silva constata uma "boa vontade", por parte da mídia, com relação a projetos sociais, mas, ao mesmo tempo, em vez de encontrar políticas editoriais ancoradas no Jornalismo Público, é mais fácil encontrar retrancas que se referem a Terceiro Setor e voluntariado. De maneira geral, os meios de comunicação brasileiros não se declaram praticantes do Jornalismo Público, o que revela, senão desconhecimento dessa categoria como um campo específico, pelo menos a inexistência de algo programático nas políticas editoriais. A exceção mais clara é a da TV Cultura.

\section{A experiência da TV Cultura}

A TV Cultura é o único meio brasileiro que declaradamente adotou, em meados de 2000, o Jornalismo Público como política editorial. Aqui nos propomos a relatar essa iniciativa a partir do pensamento diretivo vigente na época, registrado a partir de entrevistas com o então diretor de jornalismo da emissora, Marco Antônio Coelho Filho $^{3}$, e o diretor de qualidade Nivaldo Freixeda ${ }^{4}$, não tendo como objetivo analisar com profundidade as recentes modificações pelas quais vem passando a TV Cultura e sua programação ${ }^{5}$.

3 Coelho Filho atualmente integra a diretoria da TV Cultura no cargo de diretor de expansão.

4 Freixeda já não integra o corpo diretivo da emissora.

5 Diversos autores analisam a história e constituição da TV Cultura e a questão da TV Pública, entre eles, Laurindo Leal Filho (Atrás das câmeras: relações entre cultura, Estado e televisão. Summus Editorial, 1988) e Beth Carmona (O desafio da TV pública: uma reflexão sobre sustentabilidade e qualidade. Beth Carmona (org.). Acerp - TVE Rede Brasil: Rio de Janeiro, 2003). 


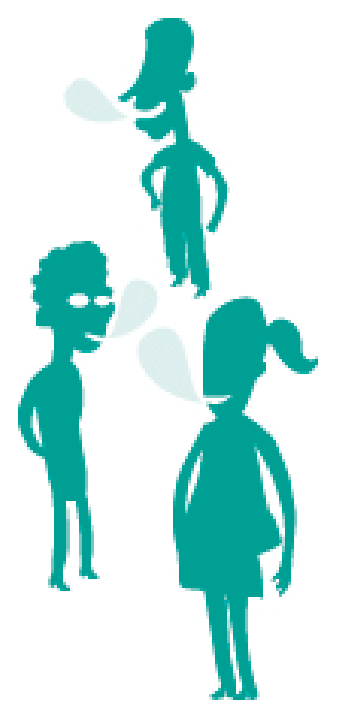

Pelo menos dois programas buscavam se inserir na proposta de Jornalismo Público: o Matéria Pública e o Diário Paulista ${ }^{6}$. Segundo Marco Antônio Coelho Filho, enquanto o jornalismo comunitário mostra o problema e cobra a solução, o Jornalismo Público mostra como os problemas podem ser tratados pelas políticas públicas: "em vez de fazer uma matéria sobre um buraco de rua e ir atrás da autoridade para que ela solucione o problema, podemos retratar como funciona a política que determina a colocação do asfalto nos bairros", exemplifica (SILVA, 2002).

A idéia é mostrar ao espectador como ele pode praticar a cidadania:

"Através de pequenos programas do gênero Faça Política, a emissora mostra como pessoas comuns podem exercer seus direitos de cidadão e cobrar das autoridades a sua atuação. A orientação seguida é: menos notícias e mais informação; fugir do superficial do jornalismo televisivo e oferecer mais informação nas reportagens, tal como informou à época Coelho Filho". (SILVA, 2002)

A TV Cultura parece não copiar simplesmente o conceito americano, pois vinha teorizando dentro da casa o que vem a ser o Jornalismo Público no entendimento da emissora. "A inspiração veio de dentro, da própria constituição institucional e jurídica da TV Cultura, que inspirou essa virada, já que somos uma TV pública", afirma Coelho Filho.

Na época, o diretor de qualidade da TV Cultura, Nivaldo Freixeda, apontava que o Jornalismo Público da TV surgiu como um desafio, uma busca por um jornalismo di-

6 Nenhum dos programas existe mais na grade de programação da emissora. Eles foram substituídos pelos jornais Cultura Meio-Dia e Jornal da Cultura. 0 Cultura Meio-Dia vai ao ar das $12 \mathrm{~h}$ às $13 \mathrm{~h}$ com ênfase no jornalismo cultural e esportivo. O Jornal da Cultura é exibido diariamente às 19h. Segundo o site da emissora, "o telejornal atende ao telespectador que, ao fim do dia, quer se informar sobre o noticiário de forma didática e clara, como propõe o Jornalismo Público". 
ferente da reprodução mecânica de porte comercial. "Uma emissora tem que ter opções de objetivos editoriais, porém, no caso da TV pública, eles têm que ser diferentes daqueles que norteiam os objetivos do jornalismo comercial”.

Em material fornecido pela própria emissora - Manual de Jornalismo Público da TV Cultura -, documento de circulação interna, são colocadas as principais teorias e questionamentos, além de algumas normas de padronização para nortear o trabalho de seus profissionais.

O Manual estava sendo escrito em conjunto pelo diretor da TV Cultura, Jorge da Cunha Lima (hoje presidente do Conselho Curador da Fundação Padre Anchieta), pelo diretor de jornalismo, Marco Antônio Coelho Filho e pelo diretor de qualidade, Nivaldo Freixeda. O projeto era discutido dentro da TV em grupos e em reuniões com as equipes, visando a propagar a nova visão e a descobrir outras possibilidades. Experiências envolvendo todos os profissionais do departamento de jornalismo também foram realizadas em um laboratório de linguagem, criado para dar forma ao nascente jornalismo (Manual, p. 5). Diferentemente das experiências americanas, a iniciativa foi isolada, deixando de lado parcerias de instituições ou universidades.

O documento ressalta a importância de um telespectador-cidadão e que isso passa pela construção de um projeto político, a partir do qual a TV assume um papel explícito de mediadora da agenda pública:

"O Jornalismo Público não busca artifícios para ocultar sua condição de mediador; pelo contrário, explicita-a deliberadamente. E o faz como gesto politico, para demarcar seu campo de ação e explorar novas formas de relacionamento com o telespectador". (Manual, p. 27. Grifo nosso)

Os autores também retomam as dimensões do interesse público com um enfoque mais humanístico, o que no Manual responde pelo conceito de universalidade. Para a TV Cultura, o interesse público está associado àquelas informações cujas conseqüências sejam mais sensíveis na vida em sociedade. O objetivo é atingir o telespectador-cidadão, não o indivíduo fragmentado, entendido na sua dimensão pessoal (Manual, p. 29). Para Freixeda,

"Nossa preocupação básica é trabalhar com temáticas que transcendam e superem a demanda do cotidiano, que trabalhem com o cotidiano histórico, que busquem os grandes temas, que de fato norteiem a vida das pessoas para além daqueles conjuntos de notícias de impactos instantâneos, mas de pouca repercussão nas vidas das pessoas".

O Manual é ousado em algumas proposições. Logo em sua introdução, afirma-se que o Jornalismo Público somente é possível em uma televisão pública e isto se deve, segundo o documento, à natureza "independente" da TVC do mercado. 
"O ordenamento jurídico dela permite superar a principal contradição das empresas que trabalham com a informação: ao mesmo tempo que desempenham uma função pública, são empreendimentos comerciais. A ambigüidade suscita dúvidas quanto à possibilidade de se harmonizar lucro e independência9". (Manual, p. 2)

Outra proposição é que o Jornalismo Público gira em torno dos assuntos governamentais, retomando, de certa forma, a idéia do cão de guarda (watchdog). Mas o caminho para se ir além nesta orientação é o da utilização de um chamado jornalismo de procedimentos, reforçando uma espécie de "algo mais" na notícia:

“...só a cobertura de processos tira o jornalismo da sua cômoda posição defensiva de apenas reagir aos eventos e o qualifica como mediador. Ele pode, ao esmiuçar temas ainda não enquadrados como 'noticias' pela mídia em geral, antecipar problemas cruciais, apontar soluções realistas, dar voz a interlocutores representativos, não a sumidades de ocasião". (Manual, p. 35)

Apesar de haver, à época, dois programas formatados dentro da filosofia do Jornalismo Público, a TV Cultura assumiu que a prática ainda estava longe do seu potencial. Um dos motivos alegados foi a própria crise vivida na época pela instituição, que se reflete na (im)possibilidade de se criar e manter novos projetos e até mesmo em se manter a programação.

Os diretores ouvidos também não excluíram as outras redes de procederem muitas vezes com muitos elementos do Jornalismo Público e até destacaram a qualidade dessas peças jornalísticas, mas, ao mesmo tempo, reforçaram que a iniciativa se perde ao se ter que abrir constantes concessões para o mercado.

\section{Considerações finais}

As atuais transformações políticas, sociais e econômicas vêm demandando da mídia uma nova postura diferente da tradição construída ao longo dos seus mais de cem anos de jornalismo informativo. Com o surgimento de novos movimentos sociais, a produção da informação como notícia deixou de ser uma exclusividade dos jornalistas midiáticos. Além disso, a construção da cidadania não se faz somente com a simples divulgação das notícias. Uma das vias de realização seria o debate.

Nesse sentido, faz-se necessária a revisão do papel da imprensa quanto ao agir político. O JP surge como alternativa aos jornalistas e como importante instrumento

9 Em 2006, a TV Cultura realizou concessões radicais em sua programação, inserindo anúncios comerciais (antes, eram apenas institucionais) e programas de auditório de cunho popular, como o da apresentadora Silvia Poppovic. 
de construção da cidadania. A intenção do Jornalismo Público é de que a imprensa torne-se mais do que o palco no qual as diversas vozes sociais possam dialogar e que realize, deste modo, a ação política característica dos tempos atuais. O JP é muito mais predisposto a trabalhar com a diversidade de opiniões e pode ser mais eficiente no conflito.

Diante deste quadro, e como mostrado anteriormente, podemos identificar o surgimento de bases político-filosóficas do Jornalismo Público como mediador e ator social e político. Escapando das críticas ao jornalismo informativo, sem ao mesmo tempo descartá-lo, os dois podem caminhar juntos em seus propósitos.

No Brasil, algumas iniciativas indicam que está se buscando uma nova configuração de Jornalismo Público. Os conceitos surgidos nos Estados Unidos estão sendo revistos e adaptados para a nossa realidade, levando-se em conta nossas demandas sociais. Apesar do aparente abandono do projeto de Jornalismo Público da TV Cultura, essa emissora foi a única a adotar, desenvolver e tentar implementar uma iniciativa tendo como moldes uma nova relação com o público.

Cabe aos jornalistas brasileiros romperem a barreira dos "dogmas" jornalísticos e criar novos modos para aprofundar suas ligações com a sociedade civil. Isto pode passar pela associação com ONGs, com universidades e até mesmo aproveitando todo o potencial da interdisciplinaridade de outras profissões, como as Relações Públicas, hoje atividade bem desenvolvida no que diz respeito a seus conceitos e fazeres.

Certamente, a grande lição deixada pelo movimento do JP é que a realidade não pode ser vista apenas pela razão objetiva, mas demanda, por parte do jornalista, o reconhecimento das várias faces que a compõem. Há uma necessidade de que este profissional rompa a barreira do espelho e busque ver o que existe além dele. Aliás, isto é algo que o jornalismo sempre teve medo de ousar tentar.

\section{Bibliografia}

CASTELLANOS, Ana María Miralles. Periodismo público: un reto a la construcción de opinión pública. Comunicación para construir lo público - Revista do $12^{\circ}$ Congresso Latino Americano de Estudiantes de Comunicación Social. Bogotá - CAB, 1. ed. 2003.

\footnotetext{
. La construcción de lo público desde el periodismo cívico. Disponível em: <http://www.eca.usp.br/alaic/Congreso1999/2gt/Ana\%20Maria\%20Miralles.doc>. Acesso em: 16 ago. 2006.

CAVALCANTE, Rodrigo Vasconcellos. Jornalismo cidadão. Monografia (Trabalho de conclusão de curso) - Departamento de Jornalismo da Escola de Comunicações e Artes. São Paulo: Universidade de São Paulo, 1999.
}

CHAPARRO, Manuel Carlos. Linguagem dos conflitos. Coimbra: Edições Minerva Coimbra, 2001. 
JORNALISMO PÚBLICO: POR UMA NOVA RELAÇÃO COM OS PÚBLICOS • PAULO CELESTINO DA COSTA, FILHO

EKSTEROWICZ, Anthony; ROBERTS, Robert; CLARK, Adrian. (Org. TRAQUINA, Nelson). Jornalismo público e conhecimento público. Revista de Comunicação e Linguagens, Lisboa, nº 27, p.151-179, fev. 2000.

FALLOWS, James. Detonando a notícia: como a mídia corrói a democracia americana. Rio de Janeiro: Civilização Brasileira, 1997.

KUNCZIK, Michael. Conceitos de jornalismo - Norte e Sul - manual de comunicação. São Paulo: Edusp, 1997.

LASCH, Christopher. A rebelião das elites e a traição da democracia. São Paulo: Ediouro, 1996.

LEAL, Lalo. A cultura da TV. Dissertação (Mestrado em Ciências Sociais) - São Paulo: PUC, 1986.

MANUAL de Jornalismo Público da TV Cultura. 2003. (Documento interno; não publicado).

MATOS, Heloiza. Questões sobre a mídia contemporânea. In: LOPES, Boanerges; VIEIRA, Roberto Fonseca (org.). Jornalismo e relações públicas: ação e reação. Uma perspectiva conciliatória possível. Rio de Janeiro: Mauad, 2004. v. 1, p. 55-64.

ROSEN, Jay. Getting the connections right: Public Journalism and troubles in the press. $<$ http://www.tcf.org/Publications/Media/Getting_the_Connections_Right>. (O documento não está mais disponível). Acesso em: 27 ago. 2003.

SILVA, Luiz Martins da. Imprensa e cidadania: possibilidades e contradições. In: MOTTA, Luiz Gonzaga (Org.). Imprensa e poder. Brasília: Editora da Universidade de Brasília, 2002.

Jornalismo público: o social como valor-notícia. In: COMPÓS. GT de Políticas e Estratégias de Comunicação da Compós, 2002.

TRAQUINA, Nelson. O estudo do jornalismo no século XX. São Leopoldo: Editora Unisinos, 2002.

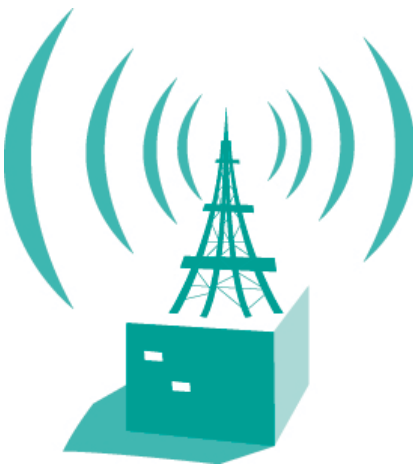

ANO $3 \cdot$ NÚMERO $4 \cdot 1$ ํ SEMESTRE DE $2006 \cdot$ organicom • 141 